\title{
An Investigation of Online Gaming Constraints and Continuance Intention in South Africa: A Student Perspective
}

\author{
Dr. R. Chinomona \\ Senior Lecturer, Faculty of Management Sciences, Vaal University of Technology \\ Private Bag X021, Vanderbijlpark, 1900, Republic of South Africa \\ e-mail: rchinos@hotmail.com
}

\section{Doi:10.5901/mjss.2013.v4n14p287}

\begin{abstract}
While it is largely agreed that online gaming business is on the growth path in South Africa, there is a dearth of researches related online gaming industry. In particular, it is not known to what extent or which online gaming constraints negatively affect consumer online gaming continuance intention. This study seeks to fill this void by attempting to make a rigorous empirical examination of the direct relationship between the six identified online gaming constraints (social, time, financial, psychological, performance and physical constraints) and online gaming continuance intention. Using a data set of 352 collected from university students in South Africa, the five posited hypotheses were supported. All the six online gaming constraints negatively affected the students' online gaming continuance intention with varying levels in a significant way. Managerial implications of the findings are discussed and limitations and future research directions are provided too.
\end{abstract}

Keywords: continuance intention, financial constraint, online gaming, performance constraint, physical constraint, psychological constraint, social constraint, time constraint

\section{Introduction}

The increasing convergence of new technologies and leisure practice has made online gaming popular (Bryce \& Rutter 2003:1). More so, with more people having high-speed Internet access, online gaming has become increasingly popular, particularly among young adults (Stoeber, Harvey, Ward \& Childs 2011:991). From a business perspective, existing evidence indicate that online game market is growing rapidly across the globe. For instance, a research by Hsiao \& Chiou (2012:75), show that worldwide revenue from online games is estimated to go from US\$15.7 billion in 2010 to US $\$ 29$ billion in 2016. Following this surge in online gaming business research seem to be on the increasing side (for example, Grusser, Thalemann \& Griffiths 2007; Herodotou, Kambouri \& Winters 2011; Liu \& Peng 2009; McMillen 2000; $\mathrm{Ng} \&$ Wiemer-Hasting 2005; Orr, Ross \& Orr 2012; Van Rooij, Schoenmakers, Van de Eijnden \& Van de Mheen 2010). One of the recent research frontier that online gaming has taken is that of consumer-based constraints of online gaming (Chen 2011:4). This is in sharp contrast to many previous studies on online gaming that by and large tended to focus on the negative aspects of gaming such as aggression, addiction, and social isolation, rather than viewing it as an activity which forms an important part of many peoples' leisure lifestyles (Bryce \& Rutter 2003:3; Yee 2006:772).

Besides, another worrying trend emerging from the extant literature related to online gaming is that, most of these studies are focused at testing a bundle of factors that influence customers' intention toward playing online games or MMOGs. For instance, factors such as usefulness (Hsu \& Lu 2004:855), enjoyment (Koo 2009:467; Wu \& Liu 2010:131), flow experience (Lee 2009:551; Orr et al, 2012), subjective norms (Lee 2009:553), presence (Teng 2010:1548), Internet addiction (Lu \& Wang 2008:499; Orr et al, 2012:739), escapism (Yee 2006:772), concentration (Grusser, Thalemann \& Griffiths 2007:294), service mechanisms (Van Rooij, Schoenmakers, Vermulst, Van Den Eijnden \& Van De Mheen 2011:206), and system design (Teng 2010:1549) are widely covered in the extent online gaming literature. However, what seems to be still lacking is a concerted effort by researchers to investigate consumer-based constraints of online gaming. Except the study by Chen (2011), that developed an instrument to measure consumer-based online gaming and empirically tested it, research in this direction remain scant. Equally disturbing is the fact that, while online gaming business is booming in Africa, academic research on the same is difficult to come by.

In view of the identified research gap aforementioned, the main objective of this study is to investigate the consumer-based constraints of online gaming in South Africa. The current study seeks to use the measurement scale developed by Chen (2011) to measure the online gaming constraints. In particular, this study will examine whether or the 
extent to which social, time, financial, physical, performance and psychological factors constrain online gaming from the perspective of South African students. The reason for choosing the student sample is that, students constitute an important segment of the online gaming community according to (Orr et al, 2012:740). In fact, there are the majority of the young online gaming community (Chen 2011:3; Van Rooij et al, 2011:207). In addition to that, the current study will examine the influence of these six constraints on online gaming continuance intention. The researcher believes that, an understanding of online gaming constraints in South Africa and their influence on consumer continuance intention will provide practical implications to the business community involved in the booming online gaming industry. Moreover, the current study being one of the first in Southern Africa to investigate this phenomenon, it will contribute new knowledge to the exiting body of online gaming literature.

This study is organized as follows: First, the literature on online gaming in South Africa and online gaming constraints are reviewed, followed by online gaming continuance intention. Then, conceptual model and research hypothesis are developed and methodology and results are presented thereafter. Finally, this study concludes with managerial implications, limitations, as well as future research directions.

\section{Literature Review}

\subsection{Online gaming in South Africa}

Computer games have been part of domestic leisure for over 25 years (Bryce \& Rutter 2003:1). With the advent of modern technology, games are now played on portable hand-held gaming devices, mobile phones, personal computers and even digital watches (Chen 2011:5). In South Africa, access to traditional computers and the Internet remains limited to small elite (Bracey \& Culver 2005:2), an observation that also holds true to most developing countries in Africa. A research conducted by Research ICT Africa found that of the only $15 \%$ of all households that have a working Computer, just 5\% reported having 'a working Internet connection' (Research ICT Africa 2009:2). In addition to that, even computers and Internet access at schools have only recently started to become available to the majority of South African sub-elite schools, but often remain behind their actual potential (Kreutzer 2009:1). Notwithstanding this limitation to online gaming, the availability of inexpensive mobile phones coupled with wireless technology, introduced a whole range of new possibilities for online gaming in South Africa (Prinsloo \& Walton 2008:100). As evidence in point, a 2005 study showed that about 18.7 million South Africans had mobile handsets and of which $80 \%$ were active customers (Van Wyk \& Van Belle 2005:14). Furthermore, wireless service is becoming more affordable to many as the service providers increased considerably in the past decade (Kreutzer 2009:2; Research ICT Africa 2009:2). If these statistics are anything to go by, then the online gaming community might be expected to growing too in South Africa. What is disturbing though, is the fact that researches targeted at investigating the constraints to online gaming on consumer gaming continuance intention given the availability of 'affordable' wireless internet services and inexpensive mobile handset, has remain scant. Such a research direction potentially has practical implications for those in online gaming business and as well as adding new knowledge to the existing academic body of literature related to online gaming business.

\subsection{Online gaming constraints and continuation intention}

Premised on the consumer-based risk factors identified by Stone \& Grønhaug (1993:40), Featherman \& Pavlou (2003:452) and Lee (2009:849) among others, Chen (2011) developed online games constraints. All in all Chen (2011:3) adopts six gaming constraints, that is, social constraint, time constraint, financial constraint, physical, constraint, performance constraint and psychological constraint. The current study adopts all the six constraints identified by Chen (2011:3) and goes a step further to investigate whether these constraints negatively online gaming continuation intention in a significant way in Africa - South Africa in particular. Constraints in this study are defined in line with Jackson (1988:204) who defined them as 'a subset of reasons for not engaging in a particular behaviour'. Below is Figure 1 - a conceptual model developed premised on the online gaming constraints and online gaming continuation intention. In this conceptualised model, the six online gaming constrains are the predictors while online gaming continuance intention is the sole outcome variable that is negatively influenced by the six online gaming constraints. 


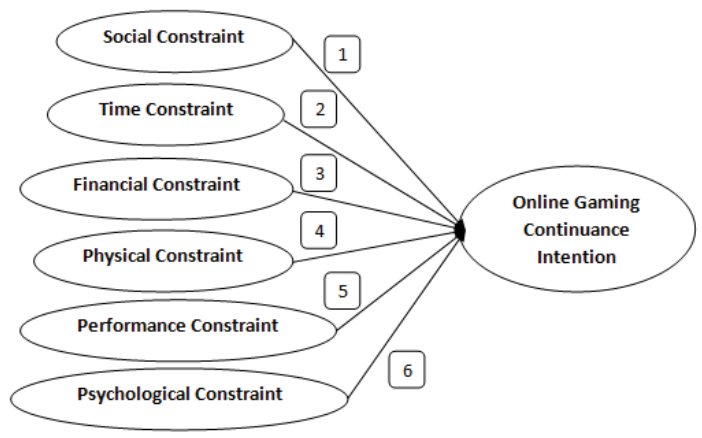

Figure 1: Conceptual Model

\section{Hypothesis Development}

\subsection{Social constraints and online gaming continuance intention}

In this study social constraint refers to the restraint the student perceives or experience as a result of fear for potential loss of status or disapproval by social groups the student belongs to because of playing online games. The social group the student belongs to can be that of friends, family members, and religious group and so on. If the social groups that the student belongs to have unfavourable perceptions about online gaming, the student might avoid online gaming out of fear of looking foolish amongst peers or losing his/her social standing in the group. In some instances, parents might disapprove online gaming for fear that it might distract the student from school work and as such might impose some sanctions on a student in order to discourage him/her from continuing to play online games in the future. In such a case, social constraints can be anticipated to be negatively associated with online gaming continuance intention. Based on the foregoing discussion and empirical findings by Chen (2011:16), this study hypothesizes that:

H1: Social constraints negatively influence students' online gaming continuance intention in South Africa.

\subsection{Time constraints and online gaming continuance intention}

Students might spend a lot of their precious time to do school work on playing online games. More so, if a student is learning how to play a new mobile game, a lot of time might be spend browsing online (c.f. Forsythe \& Shi 2003:868) and trying to sharpen his/her skills in order to play the online game perfectly well. Besides, even if the student is playing the game he/she knows and enjoys most, it is likely that the student might become obsessed out of excitement and ends up spending more time than initially intended (Kim \& Kim 2010:390). In addition, as a result of online gaming obsession a student might end up losing self-control to the point of addiction (Chen 2011:4). In this study, time constraint refers to the opportunity cost in terms of time experienced by the student for playing online games. Therefore the higher the opportunity cost of playing online games for the student in terms of time, the stronger the constraint on the student's online gaming continuance intention. Drawing from the foregoing discussion and the previous evidence (for example, Chen (2011:15), this study posits that:

H2: Time constraints negatively influence students' online gaming continuance intention in South Africa.

\subsection{Financial constraints and online gaming continuance intention}

In South Africa it is now a common eye sight to see an advert on television promoting mobile games. The audience are asked to simply dial a given number at a stated fee in order to start playing the game. A cursory observation indicates that it is mostly students who quickly get engrossed in spending more money purchasing these online new games out of curiosity and adventure. In such a case, it is possible that students might actually find themselves spending more financial resources purchasing online games more than they planned or budgeted for (Chen 2011:8). Moreover, the extent literature indicates that online games are expensive compared to those played in a traditional physical environment (Alda'S-Manzano, Lassala-Navarre, Ruiz-Mafe \& Sanz-Blas 2009:56). In this regard, students might experience more outlay of financial resources by opting for online games. However, if the financial resources happen to 
be insufficient, this might incapacitate or hamper the student's desire to continue playing online games in the future. In the current study financial constraint refers to the fear experienced by students that the actual financial cost of online gaming might exceed what they initially planned to spend for online gaming. Premised on the foregoing discussion and prior empirical evidence, the current study postulates that:

\section{H3: Financial constraints negatively influence students' online gaming continuance intention in South Africa.}

\subsection{Physical constraints and online gaming continuance intention}

It is not very unusual to find some students saying to each other that "last night I slept very late playing online games". Indeed, out of excitement and joy, students might end up over-playing online games and at times at the detriment of their health. Growing evidence indicate that, over-playing online games has some side health effects. For instance, Liu \& Peng (2009:1307) argue that over-playing online games exposes a player to potential risk of physical pain, fatigue, reduced sleeping time and skipped meals. Buttressing the same notion, Kim \& Kim (2010:391) note that online gamers who over-play are prone to health problems such as headache and eyesight problems. In such an eventuality or the fear of such possible occurrence, this constraint might discourage students from intending to continue playing online games in the future. This study defines physical constraint as the perception or fear by the student that online gaming might potentially expose him/her to health problems related to over-playing. Deducing from the aforementioned discussion and empirical evidence, the current study proposes that:

H4: Physical constraints negatively influence students' online gaming continuance intention in South Africa.

\subsection{Performance constraints and online gaming continuance intention}

It is not far from truth to suggest that the bulk of students sacrifice their meagre resources in order to play online games. The simply reason for this is that, they anticipate to experience joy, excitement and have fun. However, such anticipated excitement is subject to the assumption that the online game will perform well as expected and yet this online game performance depends on the strength of connectivity (Chen 2010:1610). For instance, if it is online mobile gaming, it is possible that signals might disappear for some reason and the student disconnected from the online game at his/her peak of enjoyment. The mere fear of such possible network dis-connectivity or mobile phone malfunction while playing online games, might actually act as a deterrent factor to students' online gaming continuance intention. In this study performance constraint refers to the student fear of losses to be incurred because of possible online gaming deficiencies, disconnection or malfunctioning while playing online games. Based on the above-mentioned arguments and previous evidence (e.g. Chen 2011:16), this hypothesizes that:

H5: Performance constraints negatively influence students' online gamingcontinuance intention in South Africa.

\subsection{Psychological constraints and online gaming continuance intention}

The mere thinking of possible negative side effects of online gaming such as addiction as professed by close mates for example, peers, relatives or even parents might cause psychological pressure, tension and mental stress in the student. Moreover, the student might not feel comfortable with disclosing personal information to get connected to online games or paying for it (Chen 2010:9; Sharp \& Rowe 2006:169). In this study, psychological constraint refers to the experience of anxiety or psychological discomfort arising from anticipated post behavioural affective reactions such as worry and regret from online gaming negative side effects. Drawing from the aforementioned discussion, the current study posits that:

H6: Psychological constraints negatively influence online gaming by students in South Africa.

\section{Research Methodology}

\subsection{Sample and Data collection}

Research data were collected from universities in Gauteng Province - in particular Vaal University of Technology and North West University (Vaal Triangle Campus) in South Africa. Some students from Vaal University of Technology, Logistics Department assisted with the distribution and collection of the questionnaires from the respondents. A random selection of the participating students was made. Of the 450 students that were approached for the study, 310 finally participated in the survey. Twelve questionnaires were discarded because of incomplete responses. A total of 252 
questionnaires were used for the final data analysis and therefore representing a response rate of 85.9 percent.

\subsection{Sample description}

Table 1 presents the profile of the participants. The profile indicates that more than sixty-one percent (61\%) of the participating students are female, while the remainder is male. About fifty-eight percent (58\%) of the participating students are undergraduates, while the remainder is postgraduate. About fifty percent (50\%) of the participating students play mobile games one to five $(1-5)$ times a day, while twenty-five percent never play at all and the remainder play more than six (6) times a day. The analysis also indicates that about ninety-one (91\%) of the participating students are aged between thirteen to twenty-five (13-25) years while the remainder are above twenty-six (26) years old.

Table 1: Sample demographic characteristics

\begin{tabular}{c|c|c||c|c|c}
\hline \hline Daily Frequency of Play & Freq & $\%$ & Gender of Student & Freq & $\%$ \\
\hline Never & 63 & 25.0 & Male & 99 & 39.3 \\
\hline $1-2$ & 66 & 26.2 & Female & 153 & 60.7 \\
\hline $3-5$ & 61 & 24.2 & Total & 252 & 100 \\
\hline $6-10$ & 38 & 15.1 & & & \\
\hline $11-20$ & 12 & 4.8 & & & \\
\hline$\leqq 21$ & 12 & 4.8 & & & \\
\hline Total & 252 & 100 & & & \\
\hline Age Group & Freq & $\%$ & Level of Education & Freq & $\%$ \\
\hline $13-18$ years & 5 & 2.0 & Undergraduate & 145 & 57.5 \\
\hline $19-25$ years & 223 & 88.5 & Postgraduates & 107 & 42.5 \\
\hline $26-35$ years & 18 & 7.1 & Total & 252 & 100 \\
\hline $36-45$ years & 5 & 2.0 & & & \\
\hline$\leqq 46$ years & 1 & 0.4 & & & \\
\hline Total & 252 & 100 & & & \\
\hline \hline
\end{tabular}

\subsection{Measurement instrument}

Research scales were operationalized mainly on the basis of previous work. Proper modifications were made in order to fit the current research context and purpose. Some three-item scales for social, time, financial, psychological and performance constraints and two-item scale on physical constraint were adapted from Chen (2011:18) previous work. "Mobile gaming Continuance intention" used a three-item scale that was adopted from Hsiao \& Chiou's (2012:83) work. All the measurement items were measured on a 5-point Likert-type scales that was anchored by 1= strongly disagree to $5=$ strongly agree to express the degree of agreement. Individual scale items are listed in Appendix

\section{Data Analysis}

\subsection{Scale accuracy analysis}

Table 2 provided below tabulated the scale items Cronbach's item-total and alpha values, composite reliability (CR) values, average variance extracted (AVE) values, shared variance (SV) and items factor loadings. Individual scale item test summaries related to research scale reliability and validity are discussed thereafter. 
Table 2: Accuracy analysis statistics

\begin{tabular}{|c|c|c|c|c|c|c|c|}
\hline \multirow{2}{*}{\multicolumn{2}{|c|}{ Research Construct }} & \multicolumn{2}{|c|}{ Cronbach's Test } & \multirow{2}{*}{$\begin{array}{c}\text { CR } \\
\text { Value }\end{array}$} & \multirow{2}{*}{$\begin{array}{l}\text { AVE } \\
\text { Value }\end{array}$} & \multirow[b]{2}{*}{$\begin{array}{c}\text { Shared } \\
\text { Variance }\end{array}$} & \multirow{2}{*}{$\begin{array}{l}\text { Factor } \\
\text { Loading }\end{array}$} \\
\hline & & $\begin{array}{l}\text { Item- } \\
\text { total }\end{array}$ & $\begin{array}{c}\alpha \\
\text { value }\end{array}$ & & & & \\
\hline \multirow{3}{*}{ Social Constraint } & SOC1 & 0.625 & \multirow{3}{*}{0.828} & \multirow{3}{*}{0.791} & \multirow{3}{*}{0.558} & \multirow{3}{*}{0.093} & $0.728^{c}$ \\
\hline & SOC2 & 0.670 & & & & & $0.749 c$ \\
\hline & SOC3 & 0.686 & & & & & $0.764^{c}$ \\
\hline \multirow{3}{*}{ Time Constraint } & $\mathrm{TIC1}$ & 0.682 & \multirow{3}{*}{0.832} & \multirow{3}{*}{0.809} & \multirow{3}{*}{0.586} & \multirow{3}{*}{0.149} & $0.774^{c}$ \\
\hline & $\mathrm{TIC2}$ & 0.708 & & & & & $0.815^{c}$ \\
\hline & TIC3 & 0.611 & & & & & $0.704^{c}$ \\
\hline \multirow{3}{*}{ Financial Constraint } & $\mathrm{FIC1}$ & 0.712 & \multirow{3}{*}{0.829} & \multirow{3}{*}{0.844} & \multirow{3}{*}{0.645} & \multirow{3}{*}{0.16} & $0.862^{c}$ \\
\hline & FIC2 & 0.697 & & & & & $0.777^{c}$ \\
\hline & FIC3 & 0.688 & & & & & $0.766^{c}$ \\
\hline \multirow{3}{*}{ Psychological Constraint } & PSC1 & 0.621 & \multirow{3}{*}{0.824} & \multirow{3}{*}{0.798} & \multirow{3}{*}{0.568} & \multirow{3}{*}{0.086} & $0.726^{c}$ \\
\hline & PSC2 & 0.701 & & & & & $0.788^{c}$ \\
\hline & PSC3 & 0.666 & & & & & $0.746^{c}$ \\
\hline \multirow{3}{*}{ Performance Constraint } & PEC1 & 0.610 & \multirow{3}{*}{0.779} & \multirow{3}{*}{0.745} & \multirow{3}{*}{0.494} & \multirow{3}{*}{0.072} & $0.702^{c}$ \\
\hline & PEC2 & 0.608 & & & & & $0.700^{c}$ \\
\hline & PEC3 & 0.614 & & & & & $0.706^{c}$ \\
\hline \multirow{2}{*}{ Physical Constraint } & PHC1 & 0.672 & \multirow{2}{*}{0.798} & \multirow{2}{*}{0.724} & & 016 & $0.762^{c}$ \\
\hline & $\mathrm{PHC2}$ & 0.662 & & & 0.547 & 0.16 & $0.744^{c}$ \\
\hline & OGCl1 & 0.736 & & & & & $0.876^{c}$ \\
\hline Online Games Continuance & $\mathrm{OGCl} 2$ & 0.714 & 0.862 & 0.885 & 0.719 & 0.008 & $0.864^{c}$ \\
\hline & OGCl3 & 0.700 & & & & & $0.802^{c}$ \\
\hline
\end{tabular}

Note: MGPE=Student Mobile Game Perceived Enjoyment; MGPEP=Student Mobile Game Perceived Ease of Play; ATMGI=Student Attitude towards Mobile Gaming Intention; MGCl=Student Mobile Gaming Continuance Intention. C.R.: Composite Reliability; AVE: Average Variance Reliability; S.V: Shared Variance. * Scores: 1 - Strongly Disagree; 3 - Neutral; 5 Strongly Agree. *significance level: a significance level $<0.05$; b significance level $<0.01$; c significance level $<0.001$

Measurement CFA model fits: $\mathrm{X}^{2}(\mathrm{df})=2.950 ; \mathrm{GFI}=0.910 ; \mathrm{NFI}=0.91 ; \mathrm{RFI}=0.92 ; \mathrm{IFI}=0.91 ; \mathrm{TLI}=0.90 ; \mathrm{CFI}=0.91$; RMSEA = 0. 076.

Table 3 given below provides the descriptive statistics, i.e. the mean scores of scales and their corresponding standard deviations. The scale construct correlations are also tabulated in in this Table 3.

Table 3: Descriptive statistics and correlations between constructs

\begin{tabular}{|l|c|c|c|c|c|c|c|c|c|}
\hline \multirow{2}{*}{\multicolumn{1}{c|}{ Construct }} & \multicolumn{2}{|c|}{ Descriptive Statistics } & \multicolumn{7}{c|}{ Construct Correlation } \\
\cline { 2 - 11 } & Mean & SD & SOC & TIC & FIC & PSC & PEC & PHC & CI \\
\hline Social Constraint & 2.356 & 0.809 & 1.000 & & & & & & \\
\hline Time Constraint & 3.538 & 0.833 & 0.065 & 1.000 & & & & & \\
\hline Financial Constraint & 3.205 & 0.985 & 0.201 & 0.386 & 1.000 & & & & \\
\hline Psychological Constraint & 2.811 & 0.837 & 0.305 & 0.269 & 0.267 & 1.000 & & & \\
\hline Performance Constraint & 3.222 & 0.699 & 0.093 & 0.308 & 0.383 & 0.291 & 1.000 & & \\
\hline Physical Constraint & 3.506 & 0.941 & 0.107 & 0.374 & 0.400 & 0.273 & 0.269 & 1.000 & \\
\hline Continuance Intention & 3.704 & 0.471 & 0.038 & 0.086 & 0.063 & 0.089 & 0.017 & 0.048 & 1.000 \\
\hline
\end{tabular}

Note: SOC=Social Constraint; TIC=Time Constraint; FIN=Financial Constraint; PSC=Psychological Constraint; PEC=Performance Constraint; PHC=Physical Constraint; Cl=Continuance Intention. * Scores: 1 - Strongly Disagree; 3 Neutral; 5 - Strongly Agree. *significance level: All were significant at level $<0.001$

The results of scale reliability tests are shown in Table 2. As can be seen, item-to-total values ranged from 0.610 to 0.736 , while Cronbach's alpha coefficients and composite reliability (C.R.) indexes are between 0.724 and 0.885 . These values exceeded the estimate criteria used by prior literature. All average variance explained (AVE) values were above 
0.4 and most approached 0.5, thus marginally accepted according to the literature (Fraering \& Minor 2006:290). These results provided evidence for marginal to acceptable levels of research scale reliability and further confirm the internal consistency measures used by this study. The scale validity was examined mainly using a confirmatory factor analysis (CFA) while all scale items were pooled together. The results are shown in Table 2 and Table 3. Convergent validity was checked by assessing if the path coefficients (loadings) between each latent construct and its corresponding scale items were statistically significant. All factor loadings in the CFA were significant (between 0.700 and 0.876 ), supporting the convergent validity of all scale items.

Discriminant validity of the research constructs was first evaluated using correlations among latent constructs of less than 1.0. All correlation values were less than 0.4 , therefore indicating that the constructs are distinct from each other. Furthermore discriminant validity was assessed by checking if the lowest AVE values for each multi-item construct were greater than the highest paired shared variance between constructs (Byrne 2006:18). The lowest AVE value of 0.494 is greater than the highest shared variance (SV) value between constructs of 0.16 . As such, all pairs of constructs reveal an adequate level of discriminant validity (see Table 2). The above results indicated that the research scales conclusively captured distinct components, thus supporting discriminant validity of the research constructs.

In accordance with the two-step procedure suggested by Anderson \& Gerbing (1988:9), prior to testing the hypotheses, confirmatory factor analysis (CFA) model fit was performed using AMOS 7, in order to examine whether the data fit the conceptualized research model. The overall acceptable model fit are indicated by Goodness-of-Fit Index

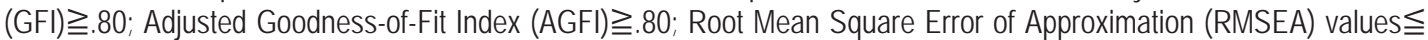
.08; Incremental Index of Fit (IFI), Tucker-Lewis Index (TLI) and Comparative Fit Index (CFI) values $\geqq .90$; and Chi-square degrees of freedom ratio (CMIN/DF) value $<3$. Recommended statistics for the final overall-model assessment show acceptable fit of the measurement model to the data: chi-square value over degrees $\left(X^{2} / \mathrm{df}\right)=1.180 ; \mathrm{GFI}=0.950 ; \mathrm{AGFI}=$ 922; $\mathrm{IFI}=0.975 ; \mathrm{TLI}=0.963 ; \mathrm{CFI}=0.973 ; \mathrm{RMSEA}=0.027$.

\subsection{Conceptual model fit assessments and research hypotheses testing}

The assessment of the proposed conceptual model proceeded using the same data set. The ratio of chi-square over degree-of-freedom was 1.204. Additional GFI, AGFI, CFI, IFI, TLI, and RMSEA values were $0.935,0.908,0.960,0.962$, 0.949 and 0.029 . All these model fit measures were above recommended thresholds, which suggested that the proposed conceptual model converged well and could be a plausible representation of the underlying empirical data structure collected in South Africa. The corresponding coefficients of the research hypotheses that posited the existence of negative relationships between the online gaming constraints and online gaming continuance intention were then observed. As seen in Table 4, all hypotheses coefficients were at least at a significant level of $p<0.01$. Thus, the proposed hypotheses $(\mathrm{H} 1-\mathrm{H} 6)$, were all supported. Individual hypothesis coefficients between online gaming constraints and online gaming continuance intention were $\mathrm{H} 1-\mathrm{H} 6(-0.28,-0.35,-0.47,-0.41,-0.33,-0.21)$ respectively.

Table 4: Results of structural equation model analysis

\begin{tabular}{lcc}
\hline Structural Paths & Hypothesis & Path Coefficients \\
\hline Student SOC $\rightarrow$ Student OGCl & $\mathrm{H} 1$ & $-0.28^{\mathrm{c}}$ \\
Student TIC $\rightarrow$ Student OGCl & $\mathrm{H} 2$ & $-0.35^{\mathrm{c}}$ \\
Student FIC $\rightarrow$ Student OGCl & $\mathrm{H} 3$ & $-0.47^{\mathrm{c}}$ \\
Student PSC $\rightarrow$ Student OGCl & $\mathrm{H} 4$ & $-0.41^{\mathrm{c}}$ \\
Student PEC $\rightarrow$ Student OGCl & $\mathrm{H} 5$ & $-0.33^{\mathrm{c}}$ \\
Student PHC $\rightarrow$ Student OGCl & $\mathrm{H} 6$ & $-0.21^{\mathrm{c}}$ \\
\hline
\end{tabular}

Structural model fits: $X^{2} /(\mathrm{df}): 1.204 ; \mathrm{GFI}: 0.935 ; \mathrm{CFI}: 0.962 ;$ TLI: 0.949; IFI = 0.960; RMSEA = 0. 029.

Note: SOC=Social Constraint; TIC=Time Constraint; FIN=Financial Constraint; PSC=Psychological Constraint; PEC=Performance Constraint; $\mathrm{PHC}=$ Physical Constraint; OGCl=Online Gaming Continuance Intention

* Scores: 1 - Strongly Disagree; 3 - Neutral; 5 - Strongly Agree

*significance level: a significance level $<0.05$; b significance level $<0.01$; c significance level $<0.001$

\section{Discussion and Conclusions}

The current research is primarily concerned with investigating the direct influence of the six online gaming constraints 
(social, time, financial, psychological, performance and physical constraints) on student online gaming continuance intention in South Africa. This study concludes that all the six online gaming constraints have significant negative influence on student online gaming continuance intention. Furthermore, according to the data analysis, it can be concluded that financial constraint has the strongest negative effects on student online gaming continuance intention. In order of negative strength, psychological, time, performance, social and physical constraints follow respectively.

The current study findings has remarkable differences from the findings by Chen (2011) using the same six online gaming constraints. While Chen (2011:17) found psychological constraint to have the strongest negative effect, this study rather, found financial constraint to have a strongest effect. In Chen's (2011) findings, financial constraint was the third in strength while in the current study psychological constraint was the second in strength. Perhaps the reason why financial constraint has the strongest effects on student online gaming continuance intention in South Africa can be explained by the fact that online gaming appear to be more expensive in South Africa when compared to Taiwan.

Based on these research findings, research implications are discussed and future research directions are suggested thereafter.

\section{Implications}

The current study has both academic and practical implications. On the academic front, this study submit that since the current studied issue has not been dealt with in relation to Sub-Saharan Africa in general and South Africa in particular, the study provides pioneering and initial evidence on the current subject. In this regard, this study contributes new knowledge on the existing body of literature related to online gaming constraints in Africa and South Africa in particular.

The practical implication relates to the fact that financial constraint has the strongest negative effect on students' online gaming continuance intention, and as such the South African business people in the online gaming industry should strive at offering online games that are inexpensive. The less expensive the online games, the lower the financial constraint on students' intention to continue playing online games. Perhaps too, the South African business people in this online gaming industry could consider offering a package of free online games together with inexpensive online games in order to stimulate the students' desire to continue playing online games in the future.

\section{Limitations and Future Research}

Although this study makes significant contributions to both academia and practice and also that due care was taken to achieve rigor, there are some limitations which open up avenues for further research. Firstly, the data were gathered from students at Two Universities in South Africa. The results might be more informative if data from other students in tertiary institutions of education such as colleges or junior and high schools across South Africa are included in the sample data. Therefore, subsequent studies might consider collecting data from schools and colleges across South Africa, including universities in other provinces of South Africa for empirical investigation. Secondly, while this study focused on South Africa, extending this study to other African countries is also another possible future research direction that might enable comparisons of results with the current study findings. Future research might also consider investigating the effects of these six online gaming constraints on other outcome variables such as online game business performance.

\section{References}

Alda'S-Manzano J., Lassala-Navarre C., Ruiz-Mafe C. \& Sanz-Blas S. (2009). The role of consumer innovativeness and perceived risk in online banking usage. The International Journal of Bank Marketing, 27(1): 53-75.

Bracey B. \& Culver T. (2005). Harnessing the potential of ICT for education: a multistakeholder approach - Proceedings from the Dublin Global Forum of the United Nations ICT Task Force, New York: United Nations Publications.

Bryce J. \& Rutter J. (2003). Gender dynamics and the social and spatial organization of computer gaming. Leisure Studies 22: 1-15

Byrne M.B. (2006). Structural equation modeling with EQS. Mahwah, NJ: Lawrence Erlbaum Associates.

Chen L.S.L. (2010). The impact of perceived risk, intangibility and consumer characteristics on online game playing. Computers in Human Behavior, 26(6): 1607-1613.

Chen L.S.L. (2011). Consumer-based leisure constraint for online gaming. The Service Industries Journal, DOI:10.1080/02642069.2011.600443

Forsythe S.M. \& Shi B. (2003). Consumer patronage and risk perceptions in internet shopping. Journal of Business Research, 56 (11): 867-875

Fraering M. \& Minor, M. S. (2006). Sense of community: an exploratory study of US consumers of financial services. International 
Journal of Bank Marketing 24 (5): 284-306.

Featherman M. \& Pavlou, P.A. (2003). "Predicting e-services adoption: A perceived risk facets perspective." International Journal of Human-Computer Studies, 59 (4): 451-474

Grusser S.M., Thalemann R. \& Griffiths M.D. (2007). Excessive computer game playing: Evidence for addiction and aggression? Cyberpsychology Behavior, 10: 290-102.

Hsu C. \& Lu H. (2004). Why do people play on-line games? An extended TAM with social influences and flow experience. Information \& Management, 41 (7): 853-868.

Herodotou C., Kambouri M. \& Winters N. (2011). The role of trait emotional intelligence in gamers' preferences for play and frequency of gaming. Computers in Human Behavior, 27: 1815-1819

Hsiao C.C. \& Chou J.S. (2012). The effects of a player's network centrality on resource accessibility, game enjoyment, and continuance intention: A study on online gaming communities. Electronic Commerce Research and Applications, 11: 75-84.

Jackson E.L. (1988). Leisure constraints: A survey of past research. Leisure Sciences, 10: 203-215.

Kim M.G. \& Kim J. (2010). Cross-validation of reliability, convergent and discriminant validity for the problematic online game use scale. Computers in Human Behavior, 26 (3): 389-398.

Koo D.M. (2009). The moderating role of locus of control on the links between experiential motives and intention to play online games. Computers in Human Behavior, 25(2): 466-474

Kreutzer T. (2009). Generation mobile: Online and digital media usage on mobile phones among low-income urban youth in South Africa'. [Online] Available Url: http://tinokreutzer.org/mobile/MobileOnlineMedia-SurveyResults-2008.pdf. (Accessed on May 2, 2012).

Liu M. \& Peng W. (2009). Cognitive and psychological predictors of the negative outcomes associated with playing MMOGs (massively multiplayer online games). Computers in Human Behavior, 25(6): 1306-1311.

Lee M.C. (2009). Understanding the behavioural intention to play online games: an extension of the theory of planned behaviour. Online Information Review, 33 (5): 849-872.

Lu H.P \& Wang SM. (2008). The role of Internet addiction in online game loyalty: an exploratory study. Internet Research, 18 (5): 499 519

Mcmillen J. (2000). Online gambling: Challenges to national sovereignty and regulation. Prometheus, 18 (4): 20-38.

Ng B.D. \& Wiemer-Hastings P. (2005). Addiction to the Internet and online gaming. Cyber-Psychology and Behavior, 8 (2): $110-113$.

Orr E.S., Ross C. \& Orr R.R. (2012). Trait and symptom differences between factions in online gaming: The vulnerable side of evil. Computers in Human Behavior, 28: 739-743

Prinsloo M. \& Walton M. (2008). Yearbook 2008: African media, African children, Göteborg: Nordicom, Göteborgs universitet, chapter Situated responses to the digital literacies of electronic communication in marginal school settings, pp. 99-116.

Research Ict Africa (Ria). (2009). RIA e-access \& usage household survey (database). [Online] Available Url: http://www.ResearchICTAfrica.net. (Accessed May 2, 2012).

Sharp, C.E., \& Rowe, M. (2006). Online games and e-business: Architecture for integrating business models and services into online games. IBM Systems Journal, 45(1): 161-179.

Stoeber J., Harvey M., Ward J.A. \& Childs J.H. (2011). Passion, craving, and affect in online gaming: Predicting how gamers feel when playing and when prevented from playing when playing and when prevented from playing. Personality and Individual Differences, 51: 991-995

Stone R.N. \& Grønhaug K. (1993). Perceived risk: Further consideration for the marketing discipline. European Journal of Marketing, 27(3): 39-50.

Teng C.I. (2010). Customization, immersion satisfaction, and online gamer loyalty. Computers in Human Behavior, 26 (6): $1547-1554$.

Van Wyk S. \& Van Belle J.P. (2005). Adoption factors for mobile gaming in South Africa. Proceedings of the 5th International Business Information Management Conference (IBIMA), 13-15 th December 2005, Cairo; Egypt.

Van Rooij A.J., Schoenmakers T.M., Van De Eijnden R.J.J.M \& Van De Mheen D. (2010). Compulsive internet use: The role of online gaming and other internet applications. Journal of Adolescent Health, 4: 51-57

Van Rooij A.J., Schoenmakers T.M., Vermulst A.A., Van Den Eijnden, R.J.J.M. \& Van De Mheen D. (2011). Online video game addiction: identification of addicted adolescent gamers. Addiction, 106(1): 205-212. doi:10.1111/j.1360-0443.2010.03104.

Wu J. \& Liu D. (2010). The effects of trust and enjoyment on intention to play online games. Journal of Electronic Commerce Research, 8 (2): 128-140.

Yee N. (2006). Motivations for play in online games. Cyber-Psychology \& Behavior, 9 (6): 772-775. 
